\begin{tabular}{|l|l|l|}
\hline \multicolumn{2}{|c|}{ PublisherInfo } \\
\hline \hline PublisherName & $:$ & BioMed Central \\
\hline \hline PublisherLocation & $:$ & London \\
\hline \hline PublisherImprintName & $:$ & BioMed Central \\
\hline \hline
\end{tabular}

\title{
NSAIDs and urinary output
}

\begin{tabular}{|l|l|l||}
\hline \multicolumn{2}{|c|}{ ArticleInfo } \\
\hline \hline ArticleID & $:$ & 4141 \\
\hline \hline ArticleDOI & $:$ & $10.1186 /$ ccf-1999-821 \\
\hline \hline ArticleCitationID & $:$ & 821 \\
\hline \hline ArticleSequenceNumber & $:$ & 78 \\
\hline \hline ArticleCategory & $:$ & Paper Report \\
\hline \hline ArticleFirstPage & $:$ & 1 \\
\hline \hline ArticleLastPage & $:$ & 3 \\
\hline \hline & & RegistrationDate : 1999-7-1 \\
ArticleHistory & $:$ & OnlineDate $\quad$ 1999-7-1 \\
\hline \hline ArticleCopyright & $:$ & Current Science Ltd1999 \\
\hline \hline ArticleGrants & $:$ & \\
\hline \hline ArticleContext & $:$ & 130541111 \\
\hline \hline
\end{tabular}




\section{Keywords}

Ketoprofen, ketorolac, non-steroidal anti-inflammatory drugs, NSAIDs, proparacetemol, urinary output

\section{Comments}

NSAIDs are widely used analgesics in hospital and general practice. The associated adverse renal effects are well described, but this study demonstrates that a reduction in diuresis is seen with a single dose of NSAID in patients without clinical evidence of hypovolaemia.

The authors advise doctors in all areas of practice to pay attention to urinary output, particularly in elderly patients, as an important signal for renal damage and the consequent risk for acute renal failure.

\section{Introduction}

The adverse effects of non-narcotic analgesics, such as non-steroidal anti-inflammatory drugs (NSAIDs) are well documented. Of particular interest in the intensive therapy unit (ITU) population, are their adverse effects on renal function which have been well described.

\section{Aims}

This prospective randomised clinical study aimed to evaluate the effect on urinary output of a single dose of two NSAIDs and a non-narcotic analgesic in an intensive care unit (ICU) population.

\section{Methods}

Following hospital ethics approval, patients admitted to this four bed general ICU in a 960 bed teaching hospital were recruited to the study if they fulfilled the inclusion criteria (listed in the paper). Patients were included in the study if they were on ICU for at least $24 \mathrm{~h}$ without arterial hypotension, 
abnormal renal function or coagulation and if they required an analgesic. The patients were randomly assigned to receive a single dose of ketorolac $30 \mathrm{mg}(\mathrm{KR})$, ketoprofen $100 \mathrm{mg}$ (KP) or proparacetamol 2 $\mathrm{g}(\mathrm{PP})$, without blinding of staff or patient. Before and after drug administration, clinical measures including hourly urine output, arterial pressure, heart rate, central venous pressure and axillary temperature were recorded. Laboratory measures such as blood urea, creatinine and potassium were also measured. Narcotic analgesia was prescribed to those patients who did not have adequate pain relief and diuretics were avoided during the $12 \mathrm{~h}$ following drug administration.

\section{Results}

Over 13 months, 63 patients were enrolled in the study ( 21 in each group). In three patients there was deviation from the protocol but they were included in the analysis on an intention to treat basis. Analysis revealed no significant differences in the groups in demographic or clinical data.

In the $3 \mathrm{~h}$ after drug administration the hourly diuresis in the patients in group PP was significantly higher than that of the other groups. The hourly diuresis in group KR reduced significantly from the second to the sixth hour compared with the urinary output in the hour before drug administration. All other variables apart from axillary temperature were unchanged. Axillary temperature was significantly reduced in group $\mathrm{KP}$ in the $12 \mathrm{~h}$ following drug administration.

\section{Discussion}

This study compared a recently available NSAID (ketorolac) with an older, frequently used drug (ketoprofen) and with proparacetamol, which appears to selectively inhibit brain prostaglandin synthesis and is not known to have effects on renal function. The doses used were those used in clinical practice. The study confirms that a single dose of proparacetamol does not affect urinary output. Both the NSAIDs studied reduced the diuresis. This was at a maximum in the third hour which seems to be larger and longer lasting following ketorolac than after ketoprofen. The authors hypothesise that a relative hypovolaemia was present and that the NSAID, secondary to an inhibition of prostaglandin synthesis, reduced the diuresis. Even a single dose in this study was sufficient to cause a reduction in hourly urinary output. This has not been previously reported in the literature.

\section{References}

1. Capuzzo M, Carrer S, Sgarbi A, Verri M, Alvisi R, Gritti G: The effect of single-dose non-steroidal anti-inflammatory drugs on urinary output. Clin Intens Care. 1999, 10: 55-60. 